\title{
Characterization of the milk fat globule membrane proteome in colostrum and mature milk of Xinong Saanen goats
}

\author{
Yuxue Sun, ${ }^{1,2} \odot$ Cuina Wang, ${ }^{1,2} \odot$ Xiaomeng Sun, ${ }^{1} \odot$ Shilong Jiang, ${ }^{3}$ and Mingruo Guo ${ }^{1,4 *}$ \\ ${ }^{1}$ Key Laboratory of Dairy Science, Northeast Agricultural University, Ministry of Education, Harbin, Heilongjiang, 150030, China \\ ${ }^{2}$ Department of Food Science, College of Food Science and Engineering, Jilin University, Changchun, Jilin, 130062, China \\ ${ }^{3}$ Feihe Dairy Company, Beijing, 100015, China \\ ${ }^{4}$ Department of Nutrition and Food Sciences, College of Agriculture and Life Sciences, University of Vermont, Burlington 05405
}

\begin{abstract}
Xinong Saanen goat milk is a major source of milk in the Chinese dairy industry. Milk fat globule membrane (MFGM) proteomes of goat colostrum and mature milk were analyzed and compared using proteomic technology. A total of 543 and 585 proteins were identified in goat colostrum and mature milk, respectively. Functional category analyses revealed that most of the MFGM proteins in both colostrum and mature milk were related to phosphoprotein and acetylation. The biological process of translation, cellular component of extracellular exosome, and molecular function of poly $(\mathrm{A})$ RNA binding were the main gene ontology annotations of both colostrum and mature milk. Pathways associated with disease and genetic information processing involved large number of proteins in colostrum and mature milk, and more metabolism-related pathways were observed in mature milk. Protein-protein interaction network analyses showed that ribosome was abundant in both colostrum and mature milk. Colostrum showed more functions associated with protein processing in the endoplasmic reticulum, whereas mature milk had more oxidative phosphorylation functions. The results could provide further understanding of the unique biological properties of MFGM proteins of goat colostrum and mature milk.
\end{abstract}

Key words: proteomics, milk fat globule membrane protein, Xinong Saanen goat, colostrum, mature milk

\section{INTRODUCTION}

Milk is an irreplaceable food for newborn mammals and also an important protein source for adults. Goat milk is a major milk source in the dairy industry and has been chosen by many consumers for its rich

Received October 12, 2019.

Accepted December 18, 2019.

*Corresponding author: mguo@uvm.edu nutrients and excellent bioactivity (Haenlein, 2004; Moreno-Indias et al., 2012). Milk protein, as a key quality indicator for milk, has always been the focus of studies. Although accounting for only about 5\% of total protein in goat milk, milk fat globule membrane (MFGM) protein has attracted attention in recent years. Cebo et al. (2010) analyzed the major MFGM proteins of goat milk using SDS-PAGE. Spertino et al. (2012) separated 207 proteins from caprine MFGM by bidimensional electrophoresis, and then the potential nutraceutical function of the milk fat globules was evaluated using Caco-2 cell model. Lu et al. (2016b) identified 175 MFGM proteins from a commercial goat milk and indicated that stomatin and xanthine dehydrogenase/oxidase were significantly enriched in goat MFGM. In our previous study, 593 proteins were reported in MFGM proteome of Guanzhong goat milk using EASY-nano Liquid Chromatography combined with Orbitrap-Tandem Mass Spectrometry (Thermo Fisher Scientific, Rockford, IL; Sun et al., 2019).

Colostrum shows differences in protein composition compared with mature milk (Georgiev, 2008; Kirovski et al., 2014). Previous studies on comparative proteomes of MFGM proteins in colostrum and mature milk mostly focused on human and bovine milk (Reinhardt and Lippolis, 2008; Yang et al., 2016; Yang et al., 2017; Cao et al., 2018). A comparison of MFGM proteomes in Guanzhong goat colostrum and mature milk was previously reported ( $\mathrm{Lu}$ et al., 2016a). However, differences in milk protein composition also occur between goat breeds (Costa et al., 2014). Information about MFGM proteomes of goat colostrum and mature milk in Xinong Saanen goat is limited.

Xinong Saanen goat milk is a typical goat milk source consumed in China. The objectives of this study were to identify and characterize MFGM proteomes of colostrum and mature milk in Xinong Saanen goat using proteomic techniques. The composition, functional categories, pathways, and protein-protein interactions of MFGM proteins in goat colostrum and mature milk are discussed and compared. 


\section{MATERIALS AND METHODS}

\section{Materials}

Colostrum and mature milk samples were obtained from 30 Xinong Saanen goats after 0 to $7 \mathrm{~d}$ and $1 \mathrm{mo}$ postpartum, respectively, at Lvnengshengtai Dairy Co. Ltd. (Baoji, Shanxi, China). Protease inhibitor cocktail tablets were purchased from Roche (Mannheim, Germany). Trypsin of sequencing grade was purchased from Promega Corporation (Madison, WI). Ultracentrifugal filter was purchased from Sartorius (Göttingen, Germany). Micro BCA protein assay kit and Pierce C18 tips were both purchased from Thermo Fisher Scientific. Dithiothreitol, iodoacetamide, formic acid, trifluoroacetic acid, methanol, and acetonitrile were purchased from Sigma-Aldrich Corporation (St. Louis, MO). All other chemicals were of analytical grade and all aqueous solutions were prepared using Milli-Q-treated water (Millipore, Bedford, MA).

\section{Preparation of MFGM Proteins}

The MFGM proteins were prepared as the method described previously by Sun et al. (2019). Milk samples were centrifuged at $8,000 \times g$ at $4^{\circ} \mathrm{C}$ for $20 \mathrm{~min}$ to obtain the solid fat (upper layer). The obtained fat layer was washed 3 times with PBS $(0.1 M$, pH 6.8, $1: 5, \mathrm{vol} / \mathrm{vol}$ ) for $30 \mathrm{~min}$ under continuous shaking and then centrifuged at $5,000 \times g$ at $4^{\circ} \mathrm{C}$ for 20 min after each washing step. After removing the washing solution, the milk fat was mixed with $0.4 \%$ SDS (1:1, vol/ vol) under sonication for 1 min and then centrifuged at $15,000 \times g$ for $10 \mathrm{~min}$ at $4^{\circ} \mathrm{C}$ to obtain MFGM proteins (liquid phase). The BCA protein assay kit was used to quantify the concentration of MFGM proteins.

\section{Protein Digestion}

The MFGM proteins were digested with a filter-aided sample preparation procedure. The MFGM protein mixture $(100 \mu \mathrm{g})$ was reduced by dithiothreitol (final concentration of $10 \mathrm{mM}$ ) at $56^{\circ} \mathrm{C}$ for $30 \mathrm{~min}$, and then alkylated by iodoacetamide (final concentration of 60 $\mathrm{m} M$ ) at room temperature for $30 \mathrm{~min}$ in the dark. After that, the resulting sample was loaded on a $10-\mathrm{kDa}$ cutoff filter and washed twice with $\mathrm{pH} 8.5$ buffer solution ( $8 M$ urea in $100 \mathrm{~m} M$ Tris $/ \mathrm{HCl}$ ). The washed filter was then added to $200 \mu \mathrm{L}$ of $50 \mathrm{mM} \mathrm{NH} \mathrm{NCO}_{3}$ solution and centrifuged at $14,000 \times g$ for $15 \mathrm{~min}$ at room temperature. This step was performed twice. Finally, the sample was digested with $1.25 \mu \mathrm{g}$ of trypsin of se-

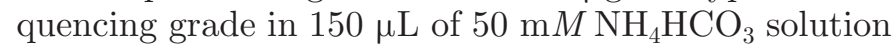
at $37^{\circ} \mathrm{C}$ overnight. The resulting peptides were desalted by $\mathrm{C} 18$ tips, then vacuum dried and stored at $-20^{\circ} \mathrm{C}$ until analysis.

\section{Nano Liquid Chromatography Tandem MS Analysis}

The peptide mixture was separated and identified using an Easy nano-LC 1000 system coupled with QExactive mass spectrometry (Thermo Fisher Scientific). Peptides $(\sim 5 \mu \mathrm{g})$ were re-suspended with $20 \mu \mathrm{L}$ of mobile phase A ( $0.1 \%$ formic acid in water). Four microliters of the re-suspended sample was injected into a C18 pre-Column $(5 \mu \mathrm{m}, 100 \mu \mathrm{m} \times 2 \mathrm{~cm})$. Then the sample was separated on a C18 analytical column $(3 \mu \mathrm{m}, 75$ $\mu \mathrm{m} \times 100 \mathrm{~nm})$ with a linear gradient of mobile phase B ( $0.1 \%$ formic acid in $80 \%$ acetonitrile). The flow rate was $300 \mathrm{~nL} / \mathrm{min}$. After that, the resulting sample was analyzed by MS. The probe heater was $300^{\circ} \mathrm{C}$ and the S-Lens radio frequency level was 60 . The MS scans were set up with a scan range of 350 to 2,000, maximum ion injection time of $50 \mathrm{~ms}$, and automatic generation control target of 3e6. Then MS/MS was conducted under a scan range of 200 to $2,000 \mathrm{~m} / \mathrm{z}$, maximum ion injection time of $45 \mathrm{~ms}$, and automatic generation control target of $1 \mathrm{e} 5$. The normalized collision energy was $27 \mathrm{eV}$ under higher energy collision dissociation fragmentation. The dynamic exclusion was $60 \mathrm{~s}$.

\section{Data Analysis}

All LC-MS/MS raw files were searched in the Ruminantia database (https://www.uniprot.org/, 2019.04.18) using Proteome Discoverer 2.2 Software (Thermo Fisher Scientific). All identified proteins were classified into biological process, cellular component, and molecular function based on their gene ontology (GO) annotations. Analyses of functional categories, Kyoto Encyclopedia of Genes and Genomes (KEGG) pathways, and protein-protein interaction (PPI) networks were also carried out for all identified proteins.

\section{RESULTS AND DISCUSSION}

\section{Identification of MFGM Proteins}

As shown in Figure 1 and Supplemental Tables S1 and S2 (https://doi.org/10.3168/jds.2019-17739), 543 and 585 proteins were identified in MFGM of goat colostrum and mature milk, respectively. Among them, 394 proteins were found in both colostrum and mature milk, 149 and 191 proteins existed only in colostrum and mature milk, respectively. The major MFGM proteins including perilipin-2, lactadherin, butyrophilin, and fatty acid-binding proteins were all identified. Casein was also found in both colostrum and mature milk. 


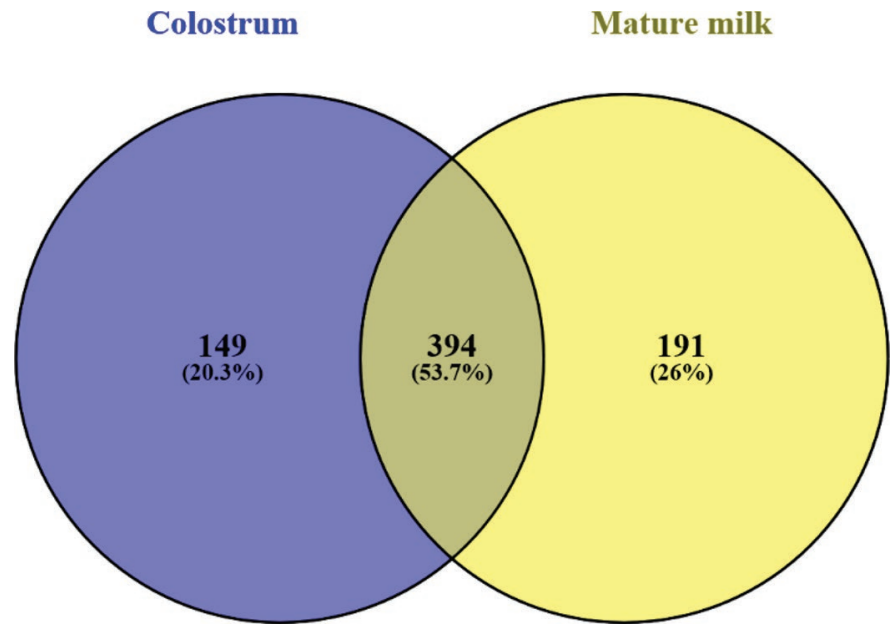

Figure 1. Venn diagram of identified milk fat globule membrane proteins in colostrum and mature milk.

Procedures of cold storage and centrifugation during the preparation of MFGM proteins may cause some minor damage to the MFGM, and casein is considered to bind to these MFGM fragments or damaged surfaces of fat globules. Similar results were reported for MFGM proteins of bovine, buffalo, and human milk (D'Ambrosio et al., 2008; Liao et al., 2011; Le et al., 2013).

\section{Functional Categories of the Identified MFGM Proteins}

All identified MFGM proteins were classified based on their UP_KEYWORDS, and the top 10 functional categories are shown in Figure 2. The MFGM proteins in colostrum and mature milk had similar categories, but the numbers and types of proteins under the same category were different.

A large number of proteins were related to posttranslational modifications in both colostrum and mature milk. Among them, phosphoprotein, acetylation, and glycoprotein ranked as the first 3 . The percentages of phosphoprotein, acetylation, and glycoprotein for colostrum were $55.32,49.81$, and $17.87 \%$, whereas those for mature milk were $57.84,48.43$, and $16.90 \%$. In our previous study on MFGM proteins of Guanzhong goat milk, phosphoprotein and acetylation were also the main categories (Sun et al., 2019). The post-translational modifications of milk proteins can be naturally formed after mRNA translation in cells, and are critical for the functions of milk proteins such as charges, hydrophobicity/hydrophilic, and sensitivity to proteases (Le et al., 2017). Post-translational modifications of proteins are also important regulators in physiology and pathology including signal transduction, neural activity, cell metabolism, apoptosis, chemotactic response, immune response, and stress response, and so on (van Rensburg et al., 2004; Delom and Chevet, 2006; Yi et al., 2012; Yu et al., 2016). Besides the post-translational modifications mentioned above, cytoplasm and membrane also aggregated many MFGM proteins in both colostrum and mature milk, which may indicate the cell component source involved in these MFGM proteins.

\section{GO Analysis of the Identified MFGM Proteins}

All identified MFGM proteins in colostrum and mature milk were classified into biological process, cellular component, and molecular function according to their gene ontology annotations (Figure 3). Results indicated that most proteins of both colostrum and mature milk were mainly involved in the biological process of translation, cellular component of extracellular exosome, and molecular function of poly(A) RNA binding.

Figure 3a shows the biological process results of MFGM proteins in colostrum and mature milk. Translation and oxidation-reduction processes involved the most proteins in both colostrum and mature milk, accounting for 9.89 and $6.08 \%$ of colostrum, respectively. For mature milk, the percentages were 9.76 and $5.57 \%$, respectively. Although the oxidation-reduction process (a metabolic process) enriched many proteins in both colostrum and mature milk, the types of proteins involved varied significantly. For colostrum, up to $40.63 \%$ of proteins aggregated in oxidation-reduction process existed only in colostrum. A similar result was also observed in mature milk. Cell-cell adhesion (4.94\%) ranked third in colostrum, followed by protein trans-

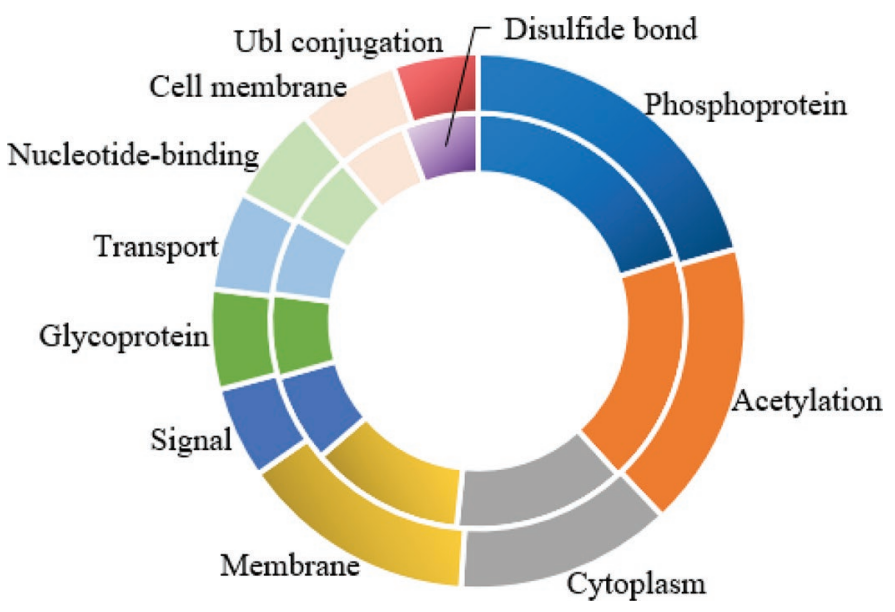

Figure 2. Top 10 functional categories of identified milk fat globule membrane proteins in colostrum (inner circle) and mature milk (outer circle) based on UP_KEYWORDS (https://david.ncifcrf.gov/home .jsp). Ubl = ubiquitin-like protein. 
port $(4.18 \%)$. Unlike those of colostrum, the third and fourth processes in mature milk were protein transport $(4.88 \%)$ and small GTPase-mediated signal transduction $(4.70 \%)$. The results are similar to those reported

a

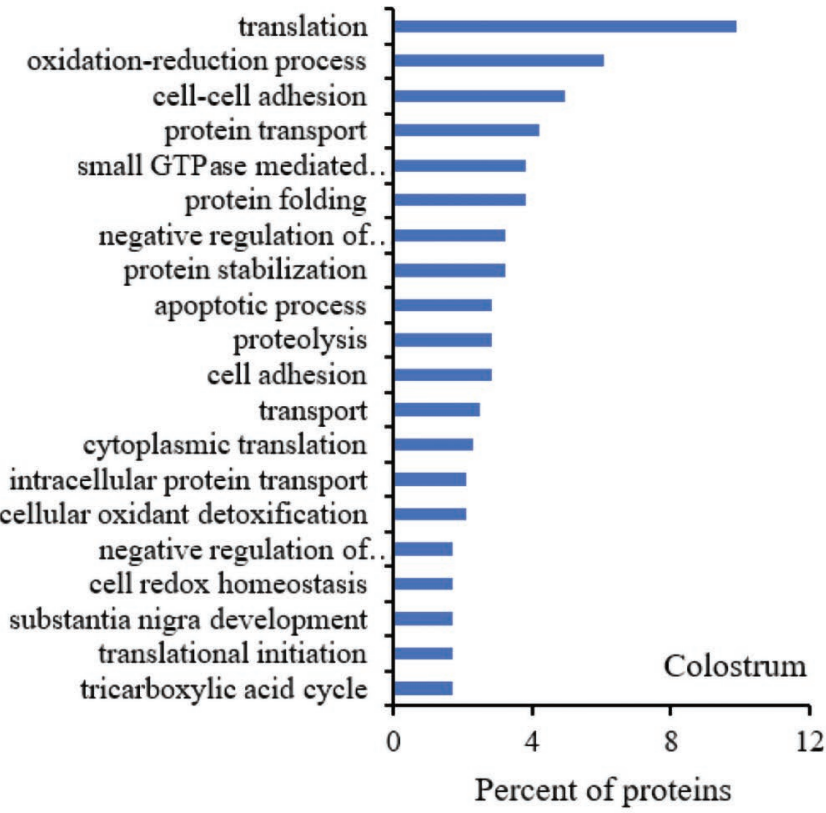

b

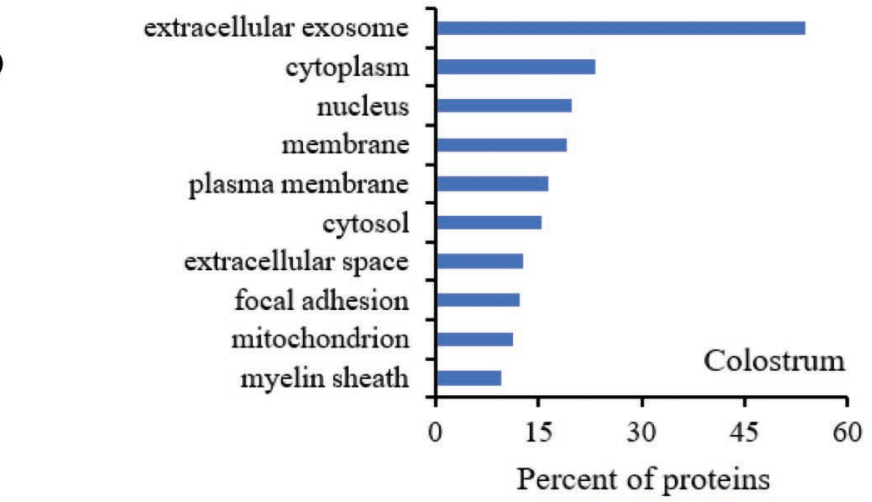

c

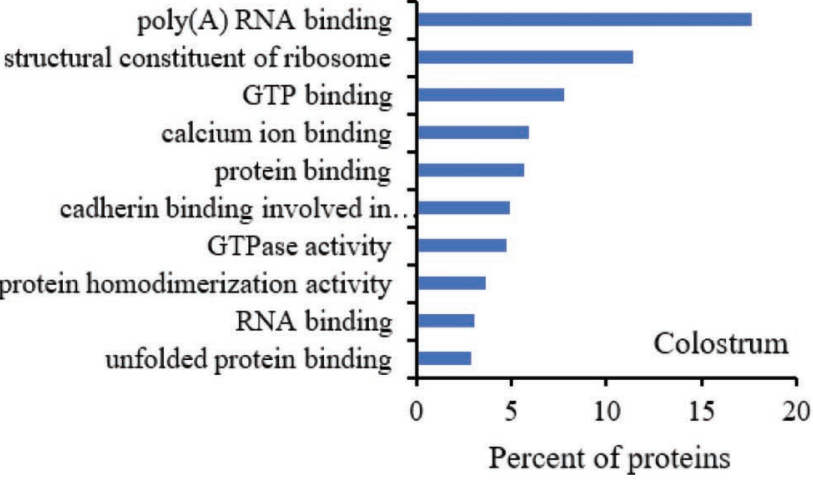

previously by Lu et al. (2016a) and Sun et al. (2019). Lu et al. (2016a) studied the MFGM proteins of colostrum and mature milk in Guanzhong goats and reported that a large number of MFGM proteins were enriched in
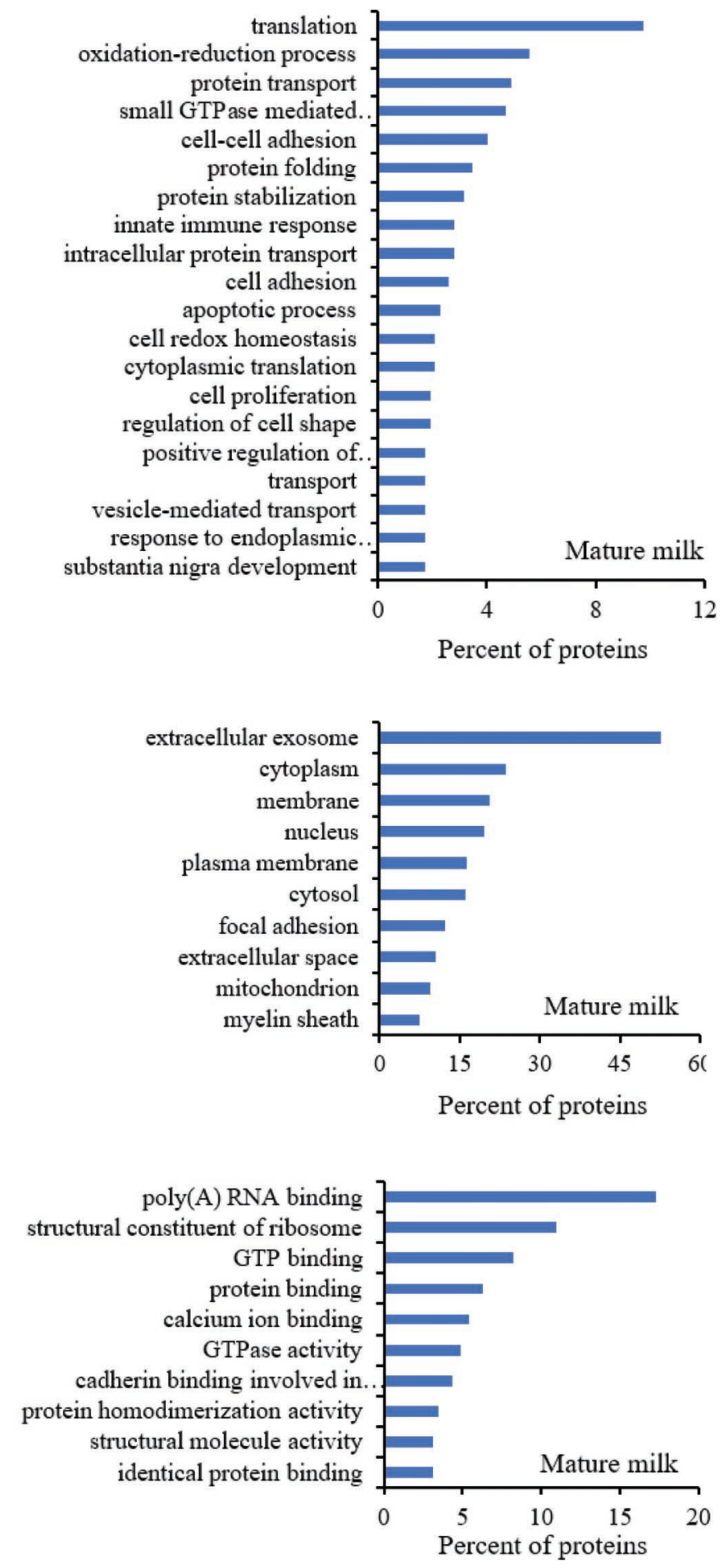

Figure 3. Gene ontology classification of identified milk fat globule membrane proteins in colostrum and mature milk based on biological process (a), cellular component (b), and molecular function (c). 
Table 1. Kyoto Encyclopedia of Genes and Genomes (KEGG) pathway analysis of milk fat globule membrane proteins from goat colostrum and mature milk

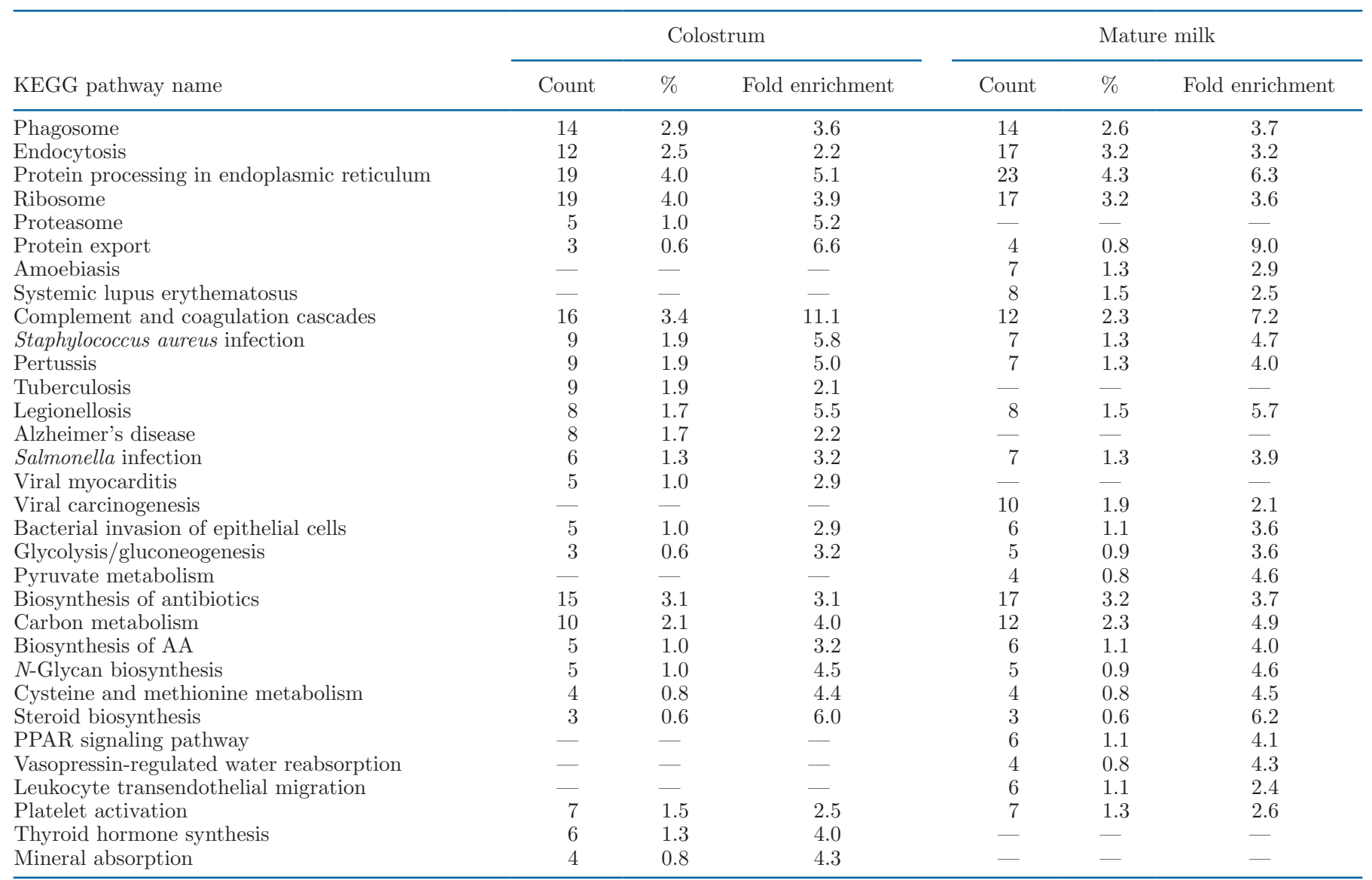

protein transport and translation. Our previous study found that oxidation-reduction process, protein transport, innate immune response, and translation were among the first 4 main biological process for MFGM proteins in Guanzhong goat mature milk (Sun et al., 2019).

Regarding the classification of the cellular component (Figure 3b), similar results were observed in colostrum and mature milk. For colostrum MFGM proteins, $53.80 \%$ fell into the extracellular exosome group, whereas the amount for mature milk was $52.61 \%$. Additionally, cytoplasm, membrane, and nucleus also enriched a large portion of proteins in both colostrum and mature milk with a different order and percentages. The results for colostrum were cytoplasm $(23.38 \%)>$ nucleus $(19.77 \%)>$ membrane $(19.01 \%)$. The results for mature milk were cytoplasm $(23.52 \%)>$ membrane $(20.56 \%)>$ nucleus $(19.69 \%)$.

For molecular function (Figure 3c), poly(A) RNA binding was the most abundant molecular function in both colostrum and mature milk with percentages of 17.68 and $17.25 \%$, respectively. This was followed by the structural constituent of ribosome and GTP binding, ranking second and third, respectively.

\section{KEGG Pathway Analysis of the Identified MFGM Proteins}

All identified MFGM proteins in the colostrum and mature milk were mainly involved in 32 KEGG pathways (Table 1). Of these, the 3 subcategories of disease, genetic information processing, and metabolism were among the top 3 for both colostrum and mature milk.

The MFGM proteins from colostrum and mature milk were highly involved in disease pathways $(12.4 \%$ for colostrum and $11.3 \%$ for mature milk), including Staphylococcus aureus infection, pertussis, and legionellosis. The reason for the presence of these disease pathways may be due to passive immunization. Proteins involved in these pathways could provide protection against infections for newborn mammals (Cavaletto et al., 2004).

Genetic information processing-related proteins, which ranked third in mature milk, were the second 
Table 2. Module analysis of the protein-protein interaction network of milk fat globule membrane proteins identified in goat colostrum

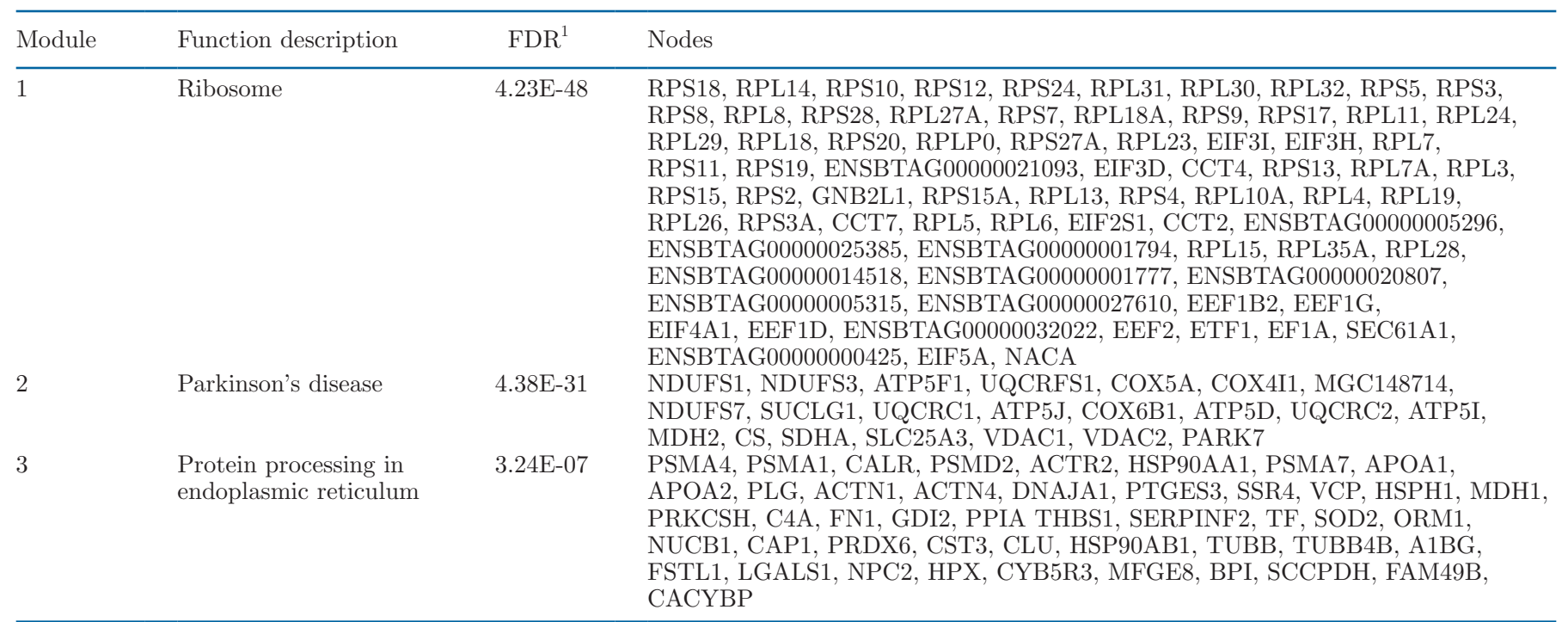

${ }^{1} \mathrm{FDR}=$ false discovery rate.

most abundant group in colostrum. Among them, protein processing in endoplasmic reticulum and ribosome enriched the most proteins of colostrum at the same percentage of $4.0 \%$, whereas for mature milk, protein processing in endoplasmic reticulum (4.3\%) ranked first, followed by ribosome $(3.2 \%)$.

Unlike colostrum, MFGM proteins of mature milk showed a larger portion and more metabolism-related pathways. Among these, several metabolism-related pathways, such as biosynthesis of antibiotics, carbon metabolism, and biosynthesis of AA, enriched a large number of proteins in both colostrum and mature milk. Interestingly, the pathway of complement and coagulation cascades was also observed in colostrum and mature milk with levels of 3.4 and $2.3 \%$, respectively. Notably, the long-term depression pathway previously found in MFGM proteins of Guanzhong goat milk (Sun et al., 2019) was not observed in the present study. It is generally believed that long-term depression is closely related to learning and memory. A previous study reported that long-term depression proteins were detected only in a portion of milk (Lu et al., 2016a). However, the reason for this is unclear and needs to be further investigated.

\section{PPI Network Analysis of the Identified MFGM Proteins}

The PPI networks were constructed for all identified MFGM proteins of colostrum and mature milk and the first 3 modules were extracted and analyzed (Tables 2 and 3). Results revealed that colostrum showed similar functions as mature milk in the top module but differences in the second and third ones.

Colostrum MFGM proteins generated a PPI network containing 469 nodes and 7,606 edges $(P<0.001)$. The top 10 central nodes were identified from the giant network based on analysis of degree centrality, including elongation factor 1-gamma (EEF1G), elongation factor 2 (EEF2), T-complex protein 1 subunit $\beta$ (CCT2), $60 \mathrm{~S}$ acidic ribosomal protein P0 (RPLP0), receptor for activated C kinase 1 (GNB2L1), GAPDH, ribosomal protein S3 (RPS3), T-complex protein 1 subunit eta (CCT7), T-complex protein 1 subunit delta (CCT4), and 40S ribosomal protein S2 (RPS2). The highest degree value in this network was 124 (corresponding node was EEF1G), which suggested that there were 124 connections/interactions between EEF1G and other proteins. The first 3 functional modules were selected and then analyzed (Table 2). Results showed that proteins in modules 1 to 3 were mainly enriched in ribosome, Parkinson's disease, and protein processing in the endoplasmic reticulum, respectively. Protein synthesis is the basis of and essential for cell growth and metabolism. Ribosomes are responsible for the process of translation from RNA into protein, during which nascent peptide chains could be constructed and modified (Spriggs et al., 2010; Hinnebusch and Lorsch, 2012). Protein processing in endoplasmic reticulum is also involved in protein synthesis, especially those proteins that required modification, such as glycoproteins. Parkinson's disease may be related to the body's immune defense. The immune defense function of MFGM proteins were also previously reported (Hettinga et al., 2011; Lu et 
Table 3. Module analysis of the protein-protein interaction network of milk fat globule membrane proteins identified in goat mature milk

\begin{tabular}{|c|c|c|c|}
\hline Module & Function description & $\mathrm{FDR}^{1}$ & Nodes \\
\hline 2 & Endocytosis & $1.79 \mathrm{E}-10$ & $\begin{array}{l}\text { FGG, FGA, ARPC5, ARPC2, ENSBTAG00000007964, ACTR2, ACTR3, } \\
\text { CLTC, CLTA, ARPC3, HSP90B1, HSPA8, P4HB, VAMP8, APOA1, DNAJC3, } \\
\text { F5, PRKCSH, FN1, RAB5C, RAB5A, SPP1, AP2B1, C3, TF, PNPLA2, } \\
\text { NUCB1, SDC2, VAMP3, C4A. ADAM10, MFGE8 }\end{array}$ \\
\hline
\end{tabular}

${ }^{1} \mathrm{FDR}=$ false discovery rate.

al., 2016b). Results in our study may suggest that the role of MFGM proteins in protein synthesis cannot be ignored compared with the immune defense functions.

The PPI network of mature milk MFGM proteins covered 516 nodes and 7,861 edges $(P<0.001)$. For the degree centrality analysis, the first 10 central nodes were GAPDH (degree 124), EEF1G (degree 122), EEF2 (degree 119), GNB2L1 (degree 115), CCT2 (degree 114), serum albumin (degree 111), RPS3 (degree 108), CCT4 (degree 106), RPLP0 (degree 105), and CCT7 (degree 104). Regarding module analysis (Table 3), the most abundant function for proteins in module 1 was ribosome. Differently from those of colostrum, proteins in modules 2 and 3 were primarily associated with endocytosis and oxidative phosphorylation. Oxidative phosphorylation is associated with ATP production during the oxidation process. The results were consistent with the results for KEGG pathway analysis where mature milk had more metabolism-related pathways than colostrum.

\section{CONCLUSIONS}

A total of 734 MFGM proteins (543 for colostrum and 585 for mature milk) were identified and characterized in colostrum and mature milk of Xinong Saanen goat using proteomic techniques. Colostrum and mature milk were different in protein number, GO annotations,
KEGG pathways, and PPI networks. Similar GO annotations were observed in colostrum and mature milk, whereas the types of proteins involved were different. Functions associated with protein synthesis were abundant in both colostrum and mature milk. It seemed that colostrum had fewer proteins but more functions of protein processing in the endoplasmic reticulum than mature milk. More metabolism-related proteins existed in mature milk. Data could provide useful information for further understanding the MFGM proteins of both colostrum and mature milk of Xinong Saanen goats.

\section{ACKNOWLEDGMENTS}

This study was funded by a special grant of Northeast Agricultural University, Harbin, Heilongjiang, China. Author Yuxue Sun carried out the experiments and statistical analysis and drafted the manuscript. Authors Cuina Wang, Xiaomeng Sun, and Shilong Jiang participated in some experiments. Author M. Guo oversaw the project and revised the manuscript. The authors declare no conflicts of interest.

\section{REFERENCES}

Cao, X. Y., S. M. Kang, M. Yang, W. X. Li, S. Y. Wu, H. J. Han, L. H. Meng, R. Wu, and X. Q. Yue. 2018. Quantitative N-glycoproteomics of milk fat globule membrane in human colostrum and ma- 
ture milk reveals changes in protein glycosylation during lactation. Food Funct. 9:1163-1172. https://doi.org/10.1039/C7FO01796K.

Cavaletto, M., M. G. Giuffrida, and A. Conti. 2004. The proteomic approach to analysis of human milk fat globule membrane. Clin. Chim. Acta 347:41-48. https://doi.org/10.1016/j.cccn.2004.04 .026 .

Cebo, C., H. Caillat, F. Bouvier, and P. Martin. 2010. Major proteins of the goat milk fat globule membrane. J. Dairy Sci. 93:868-876. https://doi.org/10.3168/jds.2009-2638.

Costa, W. K., E. L. Souza, E. M. Beltrao-Filho, G. K. Vasconcelos, T. Santi-Gadelha, C. A. de Almeida Gadelha, O. L. Franco, and M. Magnani. 2014. Comparative protein composition analysis of goat milk produced by the Alpine and Saanen breeds in northeastern Brazil and related antibacterial activities. PLoS One 9:e93361. https://doi.org/10.1371/journal.pone.0093361.

D'Ambrosio, C., S. Arena, A. M. Salzano, G. Renzone, L. Ledda, and A. Scaloni. 2008. A proteomic characterization of water buffalo milk fractions describing PTM of major species and the identification of minor components involved in nutrient delivery and defense against pathogens. Proteomics 8:3657-3666. https://doi .org/10.1002/pmic.200701148.

Delom, F., and E. Chevet. 2006. Phosphoprotein analysis: From proteins to proteomes. Proteome Sci. 4:15. https://doi.org/10.1186/ 1477-5956-4-15.

Georgiev, I. P. 2008. Differences in chemical composition between cow colostrum and milk. Bulg. J. Vet. Med. 11:3-12.

Haenlein, G. F. W. 2004. Goat milk in human nutrition. Small Rumin. Res. 51:155-163. https://doi.org/10.1016/j.smallrumres.2003 .08 .010 .

Hettinga, K., H. van Valenberg, S. de Vries, S. Boeren, T. van Hooijdonk, J. van Arendonk, and J. Vervoort. 2011. The host defense proteome of human and bovine milk. PLoS One 6:e19433. https:/ /doi.org/10.1371/journal.pone.0019433.

Hinnebusch, A. G., and J. R. Lorsch. 2012. The mechanism of eukaryotic translation initiation: New insights and challenges. Cold Spring Harb. Perspect. Biol. 4:a011544. https://doi.org/10.1101/ cshperspect.a011544.

Kirovski, D., I. Vujanac, R. Prodanović, M. Đurić, Ž. Sladojević, and Đ. Savić. 2014. The biological significance of differences in cows and sows colostrum and milk composition. Vet. Glas. 68:175-188. https://doi.org/10.2298/VETGL1404175K.

Le, T. T., G. Debyser, W. Gilbert, K. Struijs, J. Van Camp, T. Van de Wiele, B. Devreese, and K. Dewettinck. 2013. Distribution and isolation of milk fat globule membrane proteins during dairy processing as revealed by proteomic analysis. Int. Dairy J. 32:110-120. https://doi.org/10.1016/j.idairyj.2013.05.002.

Le, T. T., H. C. Deeth, and L. B. Larsen. 2017. Proteomics of major bovine milk proteins: Novel insights. Int. Dairy J. 67:2-15. https:/ /doi.org/10.1016/j.idairyj.2016.11.016.

Liao, Y. L., R. Alvarado, B. Phinney, and B. Lonnerdal. 2011. Proteomic characterization of human milk fat globule membrane proteins during a 12 month lactation period. J. Proteome Res. 10:3530-3541. https://doi.org/10.1021/pr200149t.

Lu, J., L. Liu, X. Y. Pang, S. W. Zhang, Z. H. Jia, C. L. Ma, L. L. Zhao, and J. P. Lv. 2016a. Comparative proteomics of milk fat globule membrane in goat colostrum and mature milk. Food Chem. 209:10-16. https://doi.org/10.1016/j.foodchem.2016.04.020.
Lu, J., X. Y. Wang, W. Q. Zhang, L. Liu, X. Y. Pang, S. W. Zhang, and J. P. Lv. 2016b. Comparative proteomics of milk fat globule membrane in different species reveals variations in lactation and nutrition. Food Chem. 196:665-672. https://doi.org/10.1016/ j.foodchem.2015.10.005.

Moreno-Indias, I., D. Sanchez-Macias, N. Castro, A. Morales-delaNuez, L. E. Hernandez-Castellano, J. Capote, and A. Arguello. 2012. Chemical composition and immune status of dairy goat colostrum fractions during the first $10 \mathrm{~h}$ after partum. Small Rumin. Res. 103:220-224. https://doi.org/10.1016/j.smallrumres.2011.09.015.

Reinhardt, T. A., and J. D. Lippolis. 2008. Developmental changes in the milk fat globule membrane proteome during the transition from colostrum to milk. J. Dairy Sci. 91:2307-2318. https://doi .org/10.3168/jds.2007-0952.

Spertino, S., V. Cipriani, C. De Angelis, M. G. Giuffrida, F. Marsano, and M. Cavaletto. 2012. Proteome profile and biological activity of caprine, bovine and human milk fat globules. Mol. Biosyst. 8:967-974. https://doi.org/10.1039/C2MB05400K.

Spriggs, K. A., M. Bushell, and A. E. Willis. 2010. Translational regulation of gene expression during conditions of cell stress. Mol. Cell 40:228-237. https://doi.org/10.1016/j.molcel.2010.09.028.

Sun, Y., C. Wang, X. Sun, and M. Guo. 2019. Comparative proteomics of whey and milk fat globule membrane proteins of Guanzhong goat and Holstein cow mature milk. J. Food Sci. 84:244-253. https: //doi.org/10.1111/1750-3841.14428.

van Rensburg, S. J., P. Berman, F. Potocnik, P. MacGregor, D. Hon, and N. de Villiers. 2004. 5-and 6-glycosylation of transferrin in patients with Alzheimer's disease. Metab. Brain Dis. 19:89-96. https: //doi.org/10.1023/B:MEBR.0000027420.50736.62.

Yang, M., M. Cong, X. M. Peng, J. R. Wu, R. N. Wu, B. Liu, W. H. Ye, and X. Q. Yue. 2016. Quantitative proteomic analysis of milk fat globule membrane (MFGM) proteins in human and bovine colostrum and mature milk samples through iTRAQ labeling. Food Funct. 7:2438-2450. https://doi.org/10.1039/C6FO00083E.

Yang, M., X. M. Peng, J. R. Wu, R. N. Wu, B. A. Liu, W. H. Ye, X. $\mathrm{Xu}$, and X. Q. Yue. 2017. Differential proteomic analysis of milk fat globule membrane proteins in human and bovine colostrum by iTRAQ-coupled LC-MS/MS. Eur. Food Res. Technol. 243:901912. https://doi.org/10.1007/s00217-016-2798-6.

Yi, C., M. S. Ma, L. L. Ran, J. X. Zheng, J. J. Tong, J. Zhu, C. Y. Ma, Y. F. Sun, S. J. Zhang, W. Z. Feng, L. Y. Zhu, Y. Le, X. Q. Gong, X. H. Yan, B. Hong, F. J. Jiang, Z. P. Xie, D. Miao, H. Deng, and L. Yu. 2012. Function and molecular mechanism of acetylation in autophagy regulation. Science 336:474-477. https://doi.org/10 .1126 /science.1216990.

Yu, Q., S. H. Zhang, K. Chao, R. Feng, H. L. Wang, M. Y. Li, B. L. Chen, Y. He, Z. R. Zeng, and M. H. Chen. 2016. E3 Ubiquitin ligase RNF183 is a novel regulator in inflammatory bowel disease. J. Crohn's Colitis 10:713-725. https://doi.org/10.1093/ecco-jcc/ jjw023.

\section{ORCIDS}

Yuxue Sun (๑) https://orcid.org/0000-0003-0265-2283

Cuina Wang @ https://orcid.org/0000-0002-7528-2458

Xiaomeng Sun ๑ https://orcid.org/0000-0002-1132-8584 